\title{
Combination immunotherapy: a road map
}

\author{
Patrick A. Ott ${ }^{1 *}$, F. Stephen Hodi ${ }^{1}$, Howard L. Kaufman ${ }^{2}$, Jon M. Wigginton ${ }^{3}$ and Jedd D. Wolchok ${ }^{4}$
}

\begin{abstract}
Cancer immunotherapy and in particular monoclonal antibodies blocking the inhibitory programed cell death 1 pathway (PD-1/PD-L1) have made a significant impact on the treatment of cancer patients in recent years. However, despite the remarkable clinical efficacy of these agents in a number of malignancies, it has become clear that they are not sufficiently active for many patients. Initial evidence, for example with combined inhibition of PD-1 and CTLA-4 in melanoma and non-small cell lung cancer (NSCLC), has highlighted the potential to further enhance the clinical benefits of monotherapies by combining agents with synergistic mechanisms of action. In order to address the current progress and consider challenges associated with these novel approaches, the Society for Immunotherapy of Cancer (SITC) convened a Combination Immunotherapy Task Force. This Task Force was charged with identifying and prioritizing the most promising prospects for combinatorial approaches as well as addressing the challenges associated with developing these strategies. As a result of the extensive clinical benefit and tolerable side effects demonstrated with agents inhibiting the PD-1 pathway, an overview of current evidence to support its promising potential for use as a backbone in combination strategies is presented. In addition, key issues in the development of these strategies including preclinical modeling, patient safety and toxicity considerations, clinical trial design, and endpoints are also discussed. Overall, the goal of this manuscript is to provide a summary of the current status and potential challenges associated with the development and clinical implementation of these strategies.
\end{abstract}

Keywords: Immunotherapy, Combination, Checkpoint inhibitors, Preclinical models, Clinical trial, Endpoints

\section{Background}

The strategy of using monoclonal antibodies against inhibitory receptors on immune cells, termed immunecheckpoint blockade, for the treatment of cancer has triggered substantial enthusiasm among clinicians, scientists, and patients [1]. The efficacy of this approach was first proven in patients with advanced melanoma based on the improved overall survival (OS) of patients treated with the anti-cytotoxic $\mathrm{T}$ lymphocyte associated protein 4 (CTLA-4) directed monoclonal antibody ipilimumab $[2,3]$. The impressive anti-tumor activity of PD-1/PD-L1 blockade not only in melanoma and renal cell cancer, but also in tumors previously not considered immuneresponsive, particularly NSCLC reported initially in 2012, provided proof of concept for the efficacy of immunotherapy as a more broadly applicable tool for the treatment of cancer $[4,5]$. Since then, PD-1/PD-L1 inhibition has demonstrated remarkable anti-tumor activity, including durable responses for several years, in a broad spectrum of solid and hematological malignancies, leading to regulatory approval of an increasing list of agents in a growing number of cancers. Nevertheless, the clinical efficacy of PD-1 pathway inhibition as monotherapy has been limited to subsets of patients in most tumor types studied to date, with response rates of $20 \%$ or less in many cancers including common types such as breast, colon, and prostate cancer. While predictive biomarkers such as PD-L1 expression on tumor and immune cells [6], mutational/neoantigen load [7-9], and inflammatory gene signatures $[10,11]$ may allow enrichment of patient populations that are responsive to this therapy, combination therapies will likely be required to enhance and broaden the anti-tumor activity of immune checkpoint inhibition.

\footnotetext{
* Correspondence: patrick_ott@dfci.harvard.edu

${ }^{1}$ Dana-Farber Cancer Institute, Harvard Medical School, 450 Brookline

Avenue, Dana540C, Boston, MA 02215, USA

Full list of author information is available at the end of the article
} 


\section{Agent prioritization}

\section{Backbone of combination therapies}

The established anti-tumor activity of PD-1/PD-L1 inhibition as monotherapy in a wide spectrum of cancers coupled with its favorable toxicity profile provides a strong rationale for its use as a backbone for combinatorial strategies. Despite the vastly accelerated pace of preclinical and clinical investigation of other cancer immunotherapy agents in recent years, this combination of broad single agent activity and tolerability seen with PD1 pathway inhibition is so far unparalleled; there are no other compounds on the horizon that could take the place of PD-1 pathway inhibition for this purpose.

\section{Partnering agents with anti-PD-1/PD-L1 backbone Guiding principles}

There is emerging evidence that immune checkpoint blockade is effective primarily in tumors that are already recognized by the immune system, as manifest by a preexistent CD8+ T cell infiltrate. Broadly speaking, the lack of a spontaneous tumor directed immune response may be because of the "invisibility" of the tumor to the immune system due to tumor antigens that are not sufficiently distinct from self-antigens; alternatively, tumor cell intrinsic oncogenic pathways may actively subvert an antitumor immune response as was shown for the $\beta$ catenin pathway [12]. Approaches that have the potential to convert a "non- $\mathrm{T}$ cell inflamed" tumor into a $\mathrm{T}$ cell inflamed tumor such as novel vaccines, oncolytic virus approaches, stimulation of co-stimulatory molecules, targeted therapy (such as BRAF/MEK inhibition in BRAF mutant melanoma, ALK inhibition in ALK-rearranged NSCLC), radiation/chemotherapy, and adoptive cell therapy (T cells, CARs) should be prioritized - particularly for tumor types that have shown little response to single agent anti-PD-1/PD-L therapy and for individual patients, ideally biomarker-selected, who have lower predicted response to the PD-1/PD-L1 backbone. Strategies that primarily address additional immunosuppressive mechanisms in the tumor microenvironment, such as indoleamine 2,3-dioxgenase (IDO)inhibition, TGF- $\beta$ blockade, regulatory T cell (Treg) depletion, and angiogenesis inhibition may be particularly effective to enhance or rescue tumor responses achieved with anti-PD-1/PD-L1 monotherapy.

\section{Vaccines}

Anti-PD-1 monotherapy may be limited by the size of the pool and specificity of pre-existent tumor directed $\mathrm{T}$ cells generated by physiological interaction of the evolving tumor and the host immune system. Particularly for tumors with low mutational burden, it is conceivable that insufficient numbers of $\mathrm{T}$ cell clones are spontaneously primed by tumor antigens, and therefore, a critical threshold of $\mathrm{T}$ cells is not reached to trigger an immune infiltrate. An effective vaccine may provide the necessary stimulation to broaden the repertoire of $\mathrm{T}$ cells engaged in the anti-tumor response. The accumulating evidence for tumor neoantigens as critical target antigens for tumor rejection coupled with the striking correlation of anti-CTLA-4 and anti-PD-1 induced tumor responses with the mutational/neoantigen load in NSCLC, melanoma, and microsatellite instability (MSI) high tumors make a strong case for vaccination targeting neoantigens $[7-9,13,14]$. The most effective vaccination strategies will aim to co-administer neoantigens, or other potential antigens that can be targets for $\mathrm{T}$ cell recognition (e.g., tissue differentiation or cancer stem cell associated antigens), with strong immune-adjuvants such as TLR agonists, possibly taking advantage of new delivery systems such as novel material engineered scaffolds.

\section{Oncolytic viruses}

The oncolytic virus talimogene laherparepvec (T-VEC) has shown systemic anti-tumor activity in advanced melanoma, leading to its regulatory approval in the United States, European Union, and Australia for the treatment of melanoma [15]. Similar to vaccination, oncolytic virus therapy has the potential to induce priming of $\mathrm{T}$ cells, leading to $\mathrm{T}$ cell mediated cytolysis of directly injected as well as distant tumor metastases. In phase I trials, the combination of T-VEC with ipilimumab as well as with pembrolizumab has shown higher objective tumor responses compared to ipilimumab and pembrolizumab monotherapy [16, 17]. Larger trials testing both combinations are ongoing.

\section{Agonistic co-stimulatory antibodies}

Costimulatory molecules such as CD137 (4-1BB), CD134 (OX40), glucocorticoid-induced TNFR (GITR; CD357), and CD40 are expressed by activated $\mathrm{T}$ cells, activated natural killer (NK) cells, natural killer $\mathrm{T}$ (NKT) cells, Tregs, and other immune cells [18]. Stimulation of these molecules can lead to increased effector functions (cytokine production and cytolytic activity), restrained suppressive activity of Tregs, enhanced cytokine secretion by NK cells, and enhanced antibody-dependent cellular cytotoxicity. Preclinical single agent anti-tumor activity including durable complete responses has been shown in murine tumor models as well as in early clinical trials [19, 20]. Combined activation of CD137 and inhibition of PD-1 was synergistic in an ovarian cancer model and is currently undergoing clinical testing $[21,22]$. The inhibition of the immunologic checkpoint PD-1 and stimulation of costimulatory molecules are complementary strategies to enhance immune responses and therefore provide a strong rationale for use in combination. 


\section{Adoptive T cell therapy, CAR-T cell therapy}

Adoptively transferred $\mathrm{T}$ cells generated from tumor TILs, $\mathrm{T}$ cells bearing engineered, tumor specific $\mathrm{T}$ cell receptors, and chimeric antigen receptor (CAR) T cells all have shown remarkable anti-tumor activity in select solid and hematological malignancies [23-25]. CAR $\mathrm{T}$ cells and $\mathrm{T}$ cells with engineered tumor specific TCRs may have the ability to induce an inflamed tumor microenvironment and therefore to be promising partnering strategies with PD-1/PD-L1 blockade.

\section{CTLA-4 blockade/other checkpoint inhibitors}

The combination of PD-1/PD-L1 inhibition with blockade of the non-redundant and complementary checkpoint CTLA-4 is backed by strong pre-clinical evidence and has proven very effective in advanced melanoma patients in phase I-III trials, as manifest by rapid, durable responses in a high proportion of patients [26-28]. This remarkable success provides the rationale for ongoing clinical investigation of combined PD-1/PD-L1 and CTLA-4 inhibition in many different tumor types and the exploration of PD-1/PD-L1 inhibition in combination with inhibition of other immune checkpoints such as Tim-3 and Lag-3.

\section{Targeted therapy}

Oncogenic pathway inhibition such as BRAF and MEK inhibition in melanoma has shown many effects on tumor and immune cells, including increased expression of melanoma differentiation antigens and HLA on melanoma cells, paradoxical activation of the MAPK pathway in T lymphocytes, induction of PD-L1 expression, and inhibition of suppressive cytokines such as IL-10 and VEGF [29]. Melanoma antigen expression in human tumor samples was decreased at the time of tumor progression and restored with subsequent combined MEK/ BRAF inhibition [30]. Furthermore, increased CD8+ T cell tumor infiltration was observed in early tumor samples in patients treated with BRAF inhibition. This preclinical evidence supports the investigation of PD-1/PDL1 inhibition with BRAF/MEK inhibition and potentially with other oncogenic pathway inhibitors. The restoration of other abnormal oncogenic signals in cancer cells, such as in the Wnt- $\beta$-catenin, AKT-PI3K-mTOR, and epidermal growth factor (EGF)/EGF receptor (EGFR) signaling pathways, may also be promising strategies for combination immunotherapy approaches.

\section{Angiogenesis-inhibition}

By facilitating both the growth of cancer cells and immune suppression, tumor angiogenesis is an important link between a tumor and the immune response directed against that tumor. VEGF modulates anti-tumor immunity on multiple levels including promotion and expansion of inhibitory immune cell subsets (Tregs and MDSC), inhibition of dendritic cell (DC) maturation, suppression of $\mathrm{T}$ cell responses, and immune cell trafficking across tumor endothelia [31-33]. Combination treatment of advanced melanoma patients with ipilimumab and bevacizumab led to intense infiltration of the tumor vasculature with CD8+ T cells and CD163+ dendritic macrophages, increased E-selectin expression (indicating endothelial activation), and higher numbers of circulating memory $\mathrm{CD} 4+$ and $\mathrm{CD} 8+\mathrm{T}$ cells $\left(\mathrm{CCR} 7^{+/} \mathrm{CD}_{5} 5 \mathrm{RO}^{+}\right)$in the peripheral blood [34]. The clinical benefit appeared promising compared to historical data with ipilimumab alone. Consequently, targeting angiogenesis may be an effective strategy to increase the efficacy of PD-1/PD-L1 inhibition. Several clinical trials investigating this combination are ongoing in multiple tumors types, including melanoma, renal cell cancer, and NSCLC [33].

\section{Radiation therapy}

Radiotherapy promotes the release or expression of tumor antigens in addition to immune adjuvant-like effects, leading to stimulation of immune responses. In animal models, this "in situ tumor vaccination", while rarely effective as monotherapy, has shown synergy with various immunotherapy approaches including CTLA-4 blockade [35-37]. More recently, combined radiation and CTLA-4 blockade showed potential synergy in advanced melanoma patients [38]. Consistent with an effective vaccination, radiation when given with CTLA-4 blockade, induced diversification of the $\mathrm{T}$ cell receptor repertoire of TILs and shaped the repertoire of expanded $\mathrm{T}$ cell clones [39]. Resistance to radiation and CTLA-4 blockade was found to be mediated by upregulation of PD-L1, leading to $\mathrm{T}$ cell exhaustion. Taken together, the findings provide a rationale for combined PD-1 inhibition and radiotherapy.

\section{Inhibition of IDO}

IDO catalyzes the cleavage of L-tryptophan, resulting in the production of kynurenine. Depletion of tryptophan and accumulation of kynurenine metabolites led to increased numbers and function of Tregs and blocked the proliferation of effector $\mathrm{T}$ cells [40, 41]. IDO is expressed constitutively by tumor cells or by host immune cells such as macrophages and DCs in the tumor or lymph nodes [42,43], but can also be induced by inflammatory cytokines such as IFN- $\gamma$ during a tumor directed immune response, potentially mitigating the effectiveness of immunotherapy [44]. IDO has been implicated in promoting $\mathrm{T}$ cell resistance to anti-CTLA-4 $\mathrm{Ab}$ blockade in murine melanoma models. Combined inhibition of IDO and immune checkpoint blockade (CTLA-4, PD-1, and PD-L1) has shown T cell dependent synergy in melanoma and breast cancer mouse models. 
Based on this pre-clinical evidence, several IDO inhibitors are currently in clinical investigation as monotherapies and in combination with CTLA-4 and PD-1 inhibition. Promising response rates in NSCLC and melanoma with pembrolizumab plus the IDO inhibitor epacadostat were recently reported, leading to exploration of this combination in a phase III trial in melanoma (NCT02752074) and a recently announced expansion of this phase III program into NSCLC, renal, bladder, and head and neck cancers [45].

\section{Chemotherapy}

Chemotherapy-induced cancer cell death can promote tumor antigen presentation potentially leading to priming of tumor specific $\mathrm{T}$ cells in addition to its capacity to directly stimulate immune effectors and inhibit immune suppressive factors [46]. Therefore, chemotherapy has the potential to convert a non-inflamed tumor into an inflamed one and may thus lead to synergy with PD-1/ PD-L1 inhibition particularly in non-inflamed, chemotherapy sensitive tumors.

\section{Cytokines}

Cytokines such as granulocyte macrophage colonystimulating factor (GM-CSF) and interferon- $\alpha$ can promote $\mathrm{DC}$ function, leading to increased $\mathrm{T}$ cell priming and enhancing the activity of tumor directed $\mathrm{T}$ cells $[47,48]$. The potential for additional clinical activity with CTLA-4 blockade has been shown with both GM-CSF and interferon- $\alpha$ in patients with advanced melanoma $[49,50]$. Inhibition of immune suppressive cytokines such as TGF$\beta$ and IL-10 using neutralizing antibodies also has potential synergistic activity with PD-1/PD-L1 blockade. Other immune-potentiating cytokines that have shown activity against cancer include interleukin (IL)-2, IL-12, IL-15, IL18 , and IL-21. In a small phase I/II trial of high-dose IL-2 and escalating doses of ipilimumab in 36 patients with metastatic melanoma, a slightly higher response rate compared to historic monotherapy data $(22 \%)$ was reported [51]. Of note, on further follow-up combination treatment was associated with an unanticipated $17 \%$ complete response rate. These data support further clinical studies that of combine cytokines and PD-1/PD-L1 blockade, and several such trials are currently underway.

\section{Pre-clinical murine models for testing of combination tumor immunotherapy}

In contrast to cytotoxic and targeted therapy agents that directly kill tumor cells, tumor immunotherapy mediates tumor regression indirectly through activation of innate and adaptive host immune responses or by reversing tumor-mediated immune suppression. This implies that therapeutic responses may follow a more prolonged kinetic course and also may be associated with immune- related adverse events (irAEs), which are mediated by activated immune effector cells in various host tissues. Based on the unique mechanisms of tumor rejection and toxicity, murine models used for testing of tumor immunotherapy must incorporate interactions between established tumors, the host tumor microenvironment, and the immune system to fully evaluate the therapeutic and toxicity profiles of potential immunotherapy agents administered alone or in combination. Murine models are ideal for cancer research because tumors generally establish quickly, genetic manipulation of the host and tumors is relatively simple, and mice are easy to maintain, monitor, and assess. The characteristic features of the more commonly used murine tumor models are described in Table 1.

The standard murine model utilizes a transplantable tumor system in which cultured cell lines derived from murine tumors of various origins can be injected, typically into the subcutaneous region of a mouse. These tumor cells must be derived in the same genetic background of the mouse and allows for rapid growth, simple growth assessment, and peripheral blood can be collected or mice can be euthanized at various times for toxicity analysis. These models are particularly useful for rapid studies of potential immunotherapy drug combinations and allow for inclusion of appropriate treatment controls. The model, however, has numerous limitations, including the lack of appropriate tumor microenvironment, potential problems with limited host immune system interactions since tumors often grow quickly, and local injection may induce inflammation that can influence tumor growth or drug response. Further, if the tumor cells harbor foreign transgenes, these may serve as xenoantigens and inadvertently promote tumor rejection. In some cases, murine tumor-associated antigens have been identified and these can be used to monitor immune responses and determine if tolerance can be broken during combination immunotherapy. While transplantable tumors are usually established in the subcutaneous location of the flanks, it is possible to inject the cells orthotopically, or in natural locations in which the tumor arises, to replicate the normal local environment. The potential importance of orthotopic models has been confirmed in at least one study in which the therapeutic efficacy of immunotherapy was less prominent when the cells were implanted into the kidney compared to subcutaneous tumors [52].

In order to better mimic human tumors, spontaneous tumor models have been developed in which tumors arise in the histologic tissue of origin, and these offer the benefit of more accurately reflecting patterns of tumor growth and treatment response kinetics. Such models may also be more appropriate for development and detection of irAEs. A major drawback to these models is 
Table 1 Characteristic features of available pre-clinical murine tumor models

\begin{tabular}{|c|c|c|}
\hline Model & Advantages & Disadvantages \\
\hline $\begin{array}{l}\text { Transplantable tumor } \\
\text { - syngeneic murine } \\
\text { • xenografts from human cancer } \\
\text { cells lines } \\
\text { - patient-derived xenografts (PDX) }\end{array}$ & $\begin{array}{l}\text { - Tumors usually grow quickly } \\
\text { - Reliable and reproducible } \\
\text { - Can use different tumor cell lines } \\
\text { - Gene expression easily manipulated in cell lines }\end{array}$ & $\begin{array}{l}\text { - Rapid tumor growth may not allow time for } \\
\text { physiologic immune system interactions } \\
\text { - Does not mimic natural tumor formation } \\
\text { - Tumor microenvironment is not relevant } \\
\text { - Local injections can result in inflammation } \\
\text { altering normal host response } \\
\text { - Genetic engineering may create xenoantigens }\end{array}$ \\
\hline Orthotopic tumor & $\begin{array}{l}\text { - Allows normal tumor microenvironment to develop } \\
\text { - Maintains many of the advantages of transplantable } \\
\text { tumors }\end{array}$ & $\begin{array}{l}\text { - Often grow quickly and do not allow interactions } \\
\text { with immune system } \\
\text { - May be challenging to get tumor injected or to } \\
\text { establish in native tissue or organ }\end{array}$ \\
\hline $\begin{array}{l}\text { Spontaneous tumor } \\
\text { - Carcinogen-induced } \\
\text { - Genetically-mediated (GEMM) }\end{array}$ & $\begin{array}{l}\text { - Tumors arise in situ } \\
\text { - Tumors develop with host microenvironment } \\
\text { - Tumors may have transgenic expression of oncogenes } \\
\text { or inactivation of tumor suppressor genes } \\
\text { - Tumors may exhibit more physiologic tumor growth } \\
\text { kinetics and response to treatment } \\
\text { - Assessment of toxicity is more relevant to humans }\end{array}$ & $\begin{array}{l}\text { - Tumors may take more time to develop } \\
\text { - Heterogeneity may arise and require more animals } \\
\text { to determine therapeutic responses } \\
\text { - Tumor induction may require carcinogens or genetic } \\
\text { manipulations that alter the natural course of tumor } \\
\text { development } \\
\text { - Other cells may be affected } \\
\text { - Tumor monitoring may be difficult }\end{array}$ \\
\hline Immunodeficient mice & $\begin{array}{l}\text { - Allows study of specific immune components } \\
\text { - Can accept range of allogeneic and xenogeneic } \\
\text { tumor cells } \\
\text { - Can be used to introduce specific immune } \\
\text { effector cells through adoptive transfer }\end{array}$ & $\begin{array}{l}\text { - May be prone to infection and limited lifespan } \\
\text { - May not be able to determine impact on intact } \\
\text { immune system } \\
\text { - Leakiness can result in unanticipated immune activity } \\
\text { - May be sensitive to radiation and other treatments }\end{array}$ \\
\hline Humanized mice & $\begin{array}{l}\text { - Allow more rapid study of human tumors and } \\
\text { human immune system } \\
\text { - May more accurately replicate human tumor/ } \\
\text { immune system interactions }\end{array}$ & $\begin{array}{l}\text { - Engraftment may be low } \\
\text { - Murine immune system may interfere with human } \\
\text { elements } \\
\text { - Access to human samples can be challenging } \\
\text { - Expensive }\end{array}$ \\
\hline
\end{tabular}

that they generally require carcinogen induction or genetic manipulation, which may limit their clinical relevance. Examples of carcinogen-induced spontaneous tumors include methylcholanthrene (MCA)-induced fibrosarcomas and 7,12-dimethylbenz[a]anthracene (DMBA)/12-Otetradecanoylphorbol-13-acetate (TPA)-induced skin papillomas $[52,53]$. While these are more physiologically relevant, they often take longer for cancers to develop and may be associated with considerable heterogeneity requiring many more animals to obtain the required number of tumors and determine therapeutic activity. Further, establishing the timing of treatment may be particularly challenging since neoplastic transformation may occur over variable time periods with these models.

Genetically-engineered mouse models (GEMMs) utilize forced oncogene expression or knockout of known tumor suppressor genes, usually in a tissue-specific and/or temporally controlled manner [53,54]. There are now several well-established, genetically mediated spontaneous tumor models in use. These include several breast cancer models in which selected oncogenic transgenes are driven by promoters that drive transgene expression in the mouse mammary epithelium [55]. The transgenes include Her-2/ neu (ErbB2), polyoma middle $\mathrm{T}$ antigen (PyMT), simian virus 40 (SV40) T antigen, Ha-Ras, Wnt-1, TGF- $\alpha$, and cMyc. Oncogene expression in the MMTV-Neu and
MMTV-PyMT mice is driven by the mouse mammary tumor virus promoter, and these mice develop multifocal mammary tumors and can exhibit metastatic disease in the lungs and lymph nodes, which typically occur after the first pregnancy. In contrast, the SV40 transgenic mice develop invasive tumors without the need for hormonal manipulation. In some cases, tumors require two genetic defects to promote tumor development.

There have been over 60 spontaneous murine models of melanoma reported to date [56, 57]. This includes a model in which the RET oncogene is fused to the metallothionein-I (MT) promoter-enhancer in a mixed murine strain background (C57BL/6xBALB/c), which produced systemic skin melanosis and spontaneous benign melanocytic tumors [58]. By backcrossing the mice over 10 times into C57BL/6 mice, a line in which melanocytic lesions progressed to invasive melanoma after several months was developed, and tumors eventually metastasize to lymph nodes and visceral organs. Bosenberg has developed an especially useful model in which melanoma is driven by both BRAF mutation and PTEN loss. These mice, characterized as $\mathrm{Braf}^{\mathrm{CA}} \mathrm{Tyr}-$ creER $^{\mathrm{T} 2} \mathrm{Pten}^{\mathrm{ff} / \mathrm{fl}}$, develop melanoma after exposure to 4hydroxytamoxifen (4-HT), which induces de novo melanoma initiation [56]. A murine model of autochthonous lung tumors has been reported using adenoviral vectors 
encoding Cre recombinase, KRAS, and p53 in the pulmonary epithelia [59]. In general, the carcinogen-induced models are considered highly immunogenic with emergence of numerous neoantigens that can be recognized by the immune system. In contrast, models driven by germline mutations are typically not very immunogenic $[60,61]$.

Although it may seem counterintuitive, a number of immunodeficient murine models have been used to conduct mechanistic studies of immunotherapy. Today, there are numerous such models with selective as well as more global deficiencies in immune cells or immunologic function. These models can, thus, be classified as those with severe combined immunodeficiencies (SCID) and those with selective immunodeficiencies. The simplest immune deficient mouse was termed the nude $(n u)$ mouse, in which thymic development is thwarted and results in deficient $\mathrm{T}$ cell maturation [62]. Nude mice were originally derived from mice with defects in the Forkhead box protein N1 (FOXN1) gene [63]. These mice typically live 6-12 months, accept xenografts and allow reasonable time for tumor treatment experiments. Nude females may be unable to nurse their young due to defects in mammary gland milk production and have largely been supplanted by SCID models.

A commonly used SCID model is based on knocking out the $\mathrm{V}(\mathrm{D}) \mathrm{J}$ recombination activation gene (RAG-1). RAG- $1^{-/-}$mice lack mature $\mathrm{B}$ and $\mathrm{T}$ cells, and these mice generally will not reject transplanted tumors [64]. The potential with these mice is that subpopulations of lymphocytes can be adoptively transferred, and the therapeutic impact of various treatment regimens can be assessed with and without specific lymphocyte populations. Because of this capability, these models have provided valuable insights into the mechanisms underlying antitumor immunity [65-67]. Another SCID model uses mice with mutations in the Prkdc gene, which encodes a protein that resolves DNA strand breaks during $\mathrm{V}(\mathrm{D}) \mathrm{J}$ recombination and results in the absence of functional $\mathrm{B}$ and $\mathrm{T}$ cells $[68,69]$. These Prkdc ${ }^{\text {scid }}$ (also known as nonobese diabetic or $\mathrm{NOD}^{\text {scid }}$ ) mice do have a normal hematopoietic microenvironment, can accept both allogeneic and xenogeneic grafts, allow adoptive transfer experiments, and rarely develop mature lymphocytes. A particularly immunodeficient SCID model is the NSG mouse (NOD ${ }^{\text {scidgamma; }}$ NOD.Cg-Prkdc scid $I l 2 r g^{\text {tm } 1 W j l}$ / SzJ), a strain of inbred mice in which the Prkdc gene and IL-2 receptor gamma gene, which is critical for IL2-mediated signaling, are knocked out [70]. NSG mice lack both innate and adaptive immunity with loss of $\mathrm{B}$ cell, $\mathrm{T}$ cell, and NK cell function as well as reducedmacrophage and antigen-presenting cell function [71]. These mice are highly permissive for xenogeneic tumor engraftment and have been instrumental in studies of tumor immunotherapy and other human diseases. A variety of murine strains in which single molecular pathways are disrupted have also been generated and can be used for selective mechanistic studies.

The selection of immunodeficient murine strains for experimental studies depends on several features. The strain background is important as this may influence the H2 haplotype, tumor cell engraftment potential, and disease susceptibility. The NOD mice, for example, are prone to diabetes and lack innate immunity. The functional consequences of the genetic defects also need to be considered in strain selection. Some mice exhibit "leakiness", in which the mice may start to generate functional immune cells as they age. The emergence of mature B and T cells has been reported in Prkdc ${ }^{\text {scid }}$ mice when they are older, especially if they are housed in non-specific pathogen-free conditions. Leakiness may also be more common in certain genetic backgrounds, such as C57BL/6 J and BALB/cByJ mice. The lifespan of individual mouse strains is also an important consideration as some immunodeficient mice die at a young age, with some becoming susceptible to thymic lymphomas, and this may limit their potential for long-term experiments. Some strains may also have difficulty breeding, as occurs with female nude mice, and this can limit usefulness. Some strains are highly sensitive to radiation (e.g., Prkdc ${ }^{\text {scid }}$ mice) and this can limit irradiation prior to engraftment or prevent studies of combination approached that utilize radiation therapy. Some mice also require pathogen-free environments, and husbandry capabilities may limit the choice of model. Finally, the impact of genetic mutations and how these influence cell function should be considered. For example, mutations in perforin can decrease NK cell activity whereas defects in the IL-2 receptor gamma chain can completely eliminate NK cell function.

The improved engraftment of human tumor cells in some of the SCID mouse models has allowed the generation of so-called humanized mouse models. These models further utilize the transfer of hematopoietic stem cells or, more recently autologous peripheral blood, to reconstitute the normal human immune system [72]. While several models have been proposed with considerable progress in replicating human immune-tumor components, there is still debate about how closely the humanized mice mimic the human host. Investigators are exploring the number of cells transferred, the route of transfer, the timing and age of transfer, and irradiation sources to optimize immune engraftment. Whether these mice truly organize a relevant tumor microenvironment remains unclear, but there is some evidence that mild graft-versus-host disease (GVHD) can develop, suggesting these models may be helpful for evaluating immune system activation and emergence of irAEs [72]. Other strategies in development include engineering 
expression of various cytokines into the mice to allow for more efficient immune function. Further refinements may be necessary before these mice can be endorsed as a significant improvement over other models. The generation of humanized mice is also complicated by the need for access to human tumor tissue and hematopoietic cells, institutional review board (IRB) approval, and often a need for rapid execution of cell transfer and frequently high cost to conduct experiments.

Many of the murine models have been helpful for evaluating therapeutic activity of monotherapy and combination immunotherapy agents, but few have faithfully replicated the toxicity profiles observed in humans [73-76]. It is possible, however, that the manifestations of irAEs may be present but challenging to detect in the murine models and may depend on the length of tumor establishment, background strain of the mouse used, or subtle impact of genetic changes in some models. Despite these limitations, there has been some progress in which autoimmune side effects have been observed. This includes the appearance of vitiligo in C57BL/6 mice bearing melanoma tumors and treated with a variety of immunotherapy strategies or the induction of hypophysitis in SJL/J mice treated with multiple treatments of CTLA-4 blockade [73, 74]. A strategy to better evaluate toxicity may be to use murine models in which the particular mouse strain is more susceptible to development of autoimmune symptoms (e.g., NOD, SJL/J, etc.). Another approach may be to add additional immune regulation to the model. For example, eradication of CD4 + FoxP3 + Tregs has been reported in the DEREG mouse model where mice have been engineered to express a diphtheria toxin (DT) receptorenhanced green fluorescent protein fusion protein driven by the FoxP3 gene locus [75]. These mice permit conditional depletion of Tregs using injections of diphtheria toxin and some experiments have shown that DEREG mice may be more susceptible to autoimmune-related side effects with immunotherapy treatment [76].

The availability of numerous murine models that allow establishment of human tumors and immune system components provides an important resource for more rapidly testing rational combinations of immunotherapy agents. The large number of models further promotes more relevant systems to assess both therapeutic response and propensity for irAEs. While all models have limitations (see Table 1), the range of models allows selection of systems that most closely resemble the particular cancer, immunologic targets, and genetic factors that most closely mirror the human host and permit more rapid development of novel combination treatment strategies for clinical trials.

There has been considerable controversy regarding limitations, both real and perceived, in the utility of preclinical tumor models as tools to inform the clinical development of new oncology agents. While some limitations are certainly clear, in other instances, concerns may be driven by mouse models being used inappropriately or unrealistically, as opposed to intrinsic flaws in the models themselves. For several reasons, preclinical models may be particularly useful for cancer immunotherapy and in the development of new combination immunotherapy regimens [77]. Optimizing the dose, schedule, and configuration of immunotherapeutic combinations may be complex, yet as discussed above, is critical to additively or synergistically engage immunoregulatory mechanisms and maximize the risk-benefit profile of a given regimen. This may necessitate the comparison of a range of distinct schedules and configurations for combinations to maximize both their pharmacodynamic activity and their antitumor efficacy with acceptable tolerability. While the need for additional clinical optimization of dose and schedule is often inevitable, the assessment of new regimens in rigorous preclinical models may help to substantially focus the scope and cost of these efforts, and also may enable the interrogation of candidate clinical biomarkers to monitor the biologic activity of these combinations. Preclinical models may also enable more thorough understanding of the interaction between tumor and the host immune system in vivo, and may be utilized to enable rational, hypothesis-driven identification of mechanism-based combinations for clinical testing. In tandem with more rigorous early clinical development of combination regimens, preclinical models may play an important role in identifying and optimizing the safety, clinical activity, and overall risk-benefit profile of immunotherapeutic combinations.

\section{Safety and toxicology}

\section{Combination therapy: proof-of-concept and lessons learned in patient safety}

The pronounced clinical activity of checkpoint inhibitors including antibodies directed against CTLA-4 [2], PD-1 $[4,78]$ and PD-L1 $[5,79]$ has transformed the care of several cancers including melanoma, renal cell carcinoma, NSCLC, bladder cancer, head and neck cancer, Hodgkin lymphoma, and others. In turn, numerous preclinical studies have now demonstrated the synergistic potential of immunotherapeutic combinations [80-89]. However, it has also shown that substantive incremental toxicity can result from immunotherapeutic combinations, depending on both the patient population and the dose and schedule that is utilized [90-93]. In initial studies in patients with metastatic melanoma, marked enhancement of clinical activity was observed in patients treated with the combination of ipilimumab and nivolumab $[90,94]$ as reflected by the objective response rate 
(ORR), the kinetics and depth of tumor regression, and landmark rates of OS compared to historical experience with either ipilimumab or nivolumab alone. In subsequent randomized trials, the combination of ipilimumab and nivolumab has demonstrated superior progressionfree survival (PFS) compared to ipilimumab alone in patients with melanoma [27, 28], and this combination has now been approved by the FDA for treatment-naive patients with melanoma. The initial phase I study of ipilimumab/nivolumab demonstrated grade 3/4 drugrelated adverse events (AEs) in $53 \%$ of patients across the range of doses tested, while rates of grade $3 / 4$ AEs in the subsequent randomized phase III were $55 \%$ in patients treated with the combination versus $27.3 \%$ or $16.3 \%$ among patients treated with either ipilimumab or nivolumab alone, respectively [27, 90]. Notably, although standard doses of ipilimumab $(3 \mathrm{mg} / \mathrm{kg}$ ) could be combined safely with doses of nivolumab up to $1 \mathrm{mg} / \mathrm{kg}$, and standard doses of nivolumab ( $3 \mathrm{mg} / \mathrm{kg}$ ) could be combined safely with doses of ipilimumab up to $1 \mathrm{mg} / \mathrm{kg}$, combined administration of standard doses of both ipilimumab $(3 \mathrm{mg} / \mathrm{kg})$ and nivolumab $(3 \mathrm{mg} / \mathrm{kg}$ ) was poorly tolerated and exceeded the maximum tolerated dose (MTD) for the combination [90]. Nonetheless, despite the increase in the incidence of grade $3 / 4 \mathrm{AEs}$ in patients treated with the combination of ipilimumab and nivolumab compared to either single agent alone, it is important to note that observed events were generally qualitatively similar for patients treated with combination therapy and the individual single agents. Further, the institution of algorithm-based supportive care has also been very effective in management of patients treated with checkpoint inhibitors and no treatmentrelated deaths were attributed to the combination of ipilimumab/nivolumab in the phase III study [27]. Collectively, these observations highlight the importance of flexible approaches to optimization of the dose and schedule of immunotherapeutic combinations. This requires rigorous clinical testing of various schedules for immunotherapeutic combination early in clinical development, and may require acceptance of the use of nonstandard doses or schedules of individual agents to maximize the overall risk-benefit profile of a given combination. The importance of this consideration was further highlighted by a phase I study combining ipilimumab and the Raf inhibitor, vemurafenib, in patients with melanoma [95]. In this study, the initial cohort of patients was treated with standard doses of both ipilimumab $(3 \mathrm{mg} / \mathrm{kg}$ ) and vemurafenib (960 mg orally twice daily) administered concurrently, with plans for dose deescalation in the event of dose-limiting toxicity (DLT) on this initial dose level. Substantial increases in toxicity, in particular hepatotoxicity, were observed in patients treated at this dose/schedule. Hepatotoxicity was also observed despite a reduction in the dose of vemurafenib (720 mg orally twice daily) in combination with the standard $3 \mathrm{mg} / \mathrm{kg}$ dose of ipilimumab. As a result, this trial was terminated very early, and there has been limited subsequent development of this combination. A recent follow-on study evaluated the combination of vemurafenib and ipilimumab using a sequential schedule of administration [96]. This regimen demonstrated a substantially improved safety profile, with marked reduction in hepatotoxicity compared to the prior study that administered ipilimumab and vemurafenib concurrently. These studies clearly highlight the clinical development challenges and risks in combining immuno-oncology agents at standard doses and schedules. Attempts to combine standard doses of these two highly active agents in patients with melanoma resulted in substantial incremental toxicity without improvements in clinical benefit, and further support the notion that when immunotherapy agents are used in combination or with conventional antineoplastic agents, it is reasonable to anticipate that compromises from standard dosing and schedules are likely to be required to unlock the therapeutic potential of combination regimens with acceptable risk-benefit. The potential for additional safety concerns might suggest that dose escalation, run-in, or sequential schemas should be considered in early phase clinical development of combination regimens.

Further, active combination regimens may have very distinct safety profiles in different patient populations, as illustrated by the experience using ipilimumab + nivolumab in patients with metastatic NSCLC [91]. Although this combination demonstrated potent antitumor activity and acceptable tolerability in patients with melanoma treated with ipilimumab/nivolumab at doses as high as ipilimumab $(1 \mathrm{mg} / \mathrm{kg})$ plus nivolumab $(3 \mathrm{mg} / \mathrm{kg})$ or ipilimumab (3 $\mathrm{mg} / \mathrm{kg})$ plus nivolumab $(1 \mathrm{mg} / \mathrm{kg})$ [90], the tolerability of this combination appeared to be quite distinct in patients with NSCLC. These same dosing regimens for ipilimumab and nivolumab were poorly tolerated in initial studies in patients with NSCLC despite elimination of the use of ipilimumab beyond induction, with 22/46 (48\%) experiencing grade 3/4 AEs, 16 patients with treatment discontinuation due to AEs, and 3 drug-related deaths [91]. In addition, the overall ORR of $22 \%$ in this study was arguably no better than the $18 \%$ ORR achieved in phase I testing of nivolumab alone [4]. Additionally, a pilot study in 20 patients with glioblastoma demonstrated similar themes [92]. Here, patients were randomly assigned to treatment with either nivolumab monotherapy ( $3 \mathrm{mg} / \mathrm{kg}$ ) every 2 weeks or an induction regimen consisting of ipilimumab $(3 \mathrm{mg} / \mathrm{kg})$ plus nivolumab $(1 \mathrm{mg} / \mathrm{kg})$ every 3 weeks, followed by nivolumab (3 $\mathrm{mg} / \mathrm{kg})$ monotherapy every 2 weeks. Drug-related grade 3/4 AEs were observed in 
$8 / 10$ (80\%) patients treated with the combination of ipilimumab and nivolumab, while drug-related AEs were all grade 1 or 2 in patients treated with nivolumab alone. Treatment-related discontinuations occurred in 5/10 (50\%) patients treated with the combination compared to none in patients treated with nivolumab alone. Landmark 6-month OS rates were essentially the same in the combination $(80 \%, 8 / 10$ patients) and the nivolumab monotherapy (70\%, 7/10 patients) arms.

Subsequent studies of ipilimumab and nivolumab in patients with NSCLC have now explored alternative combination regimens with lower dose intensity, with demonstration of both improved safety and enhanced clinical activity [97]. In this study, four distinct regimens were tested in patients with NSCLC, including Arm A: ipilimumab $(1 \mathrm{mg} / \mathrm{kg})$ plus nivolumab $(1 \mathrm{mg} / \mathrm{kg})$ administered every three weeks, Arm B: ipilimumab $(1 \mathrm{mg} / \mathrm{kg})$ every 6 weeks plus nivolumab $(1 \mathrm{mg} / \mathrm{kg})$ every 2 weeks, Arm C: ipilimumab (1 mg/kg) every 12 weeks plus nivolumab (3 mg/kg) every 2 weeks, and Arm D: ipilimumab $(1 \mathrm{mg} / \mathrm{kg})$ every 6 weeks plus nivolumab $(3 \mathrm{mg} / \mathrm{kg})$ every 2 weeks. All four of the arms were clinically active, with highly favorable ORR achieved for patients treated on Arm C (39\%) and Arm D (31\%) compared to the historical experience with either nivolumab or ipilimumab alone. The ORR for patients treated on Arm A and Arm B were $13 \%$ and $25 \%$, respectively. Notably, not only were these alternative regimens highly active, but they were far better tolerated than the ipilimumab/nivolumab regimens established in patients with melanoma. The rate of grade 3/4 drug-related AEs ranged from 28 to $35 \%$ across the arms, with treatment-related discontinuations in less than $10 \%$ of patients, and no treatment-related deaths.

This collective experience with the ipilimumab/nivolumab combination highlights both the opportunity for patients using properly designed combination immunotherapy regimens, as well as the clinical development risks in not approaching the development of these regimens with both considerable flexibility and a rigorous approach to optimization of dose, schedule, and configuration of the respective agents. These studies demonstrate that regimented use of standard doses and schedules of agents based on monotherapy experience may lead to prohibitive toxicity and erroneous conclusions regarding the therapeutic potential and overall risk-benefit profile of immunotherapeutic combinations. In contrast, flexible investigation of non-standard doses and schedules early in the clinical development of combinations, may enable definition of regimens with additive or synergistic clinical activity with far more favorable safety profiles than when the same combinations are administered using the approved monotherapy doses and schedules of the respective agents. In addition, it appears clear that the optimal dose and schedule for a given combination may differ across distinct indications given differences in disease biology and/or co-morbidities in distinct patient populations.

\section{Safety considerations in early clinical testing}

Immunotherapeutic combinations may present unique challenges that must be considered with respect to the assessment and management of patient safety. In general, immunotherapy agents demonstrate unique safety profiles that may differ considerably from the majority of conventional oncology drugs. For example, treatment with checkpoint inhibitors, including monoclonal antibodies that target CTLA-4, PD-1, or PD-L1 have been associated with a variety of autoimmune-like inflammatory phenomena that appear to be driven by disruption of self-tolerance to various normal tissues including thyroid, pituitary, liver, lung, colon, eye, and skin among others [98, 99]. Increased awareness of these events, recognition of the necessity of early diagnosis and intervention with immune-suppression, as well as the development of algorithm-based guidelines for the management of these irAEs has played a key role in enabling broad use of these agents in multiple tumor types with an acceptable safety profile. Other immunotherapeutic approaches including CAR $\mathrm{T}$ cells and CD3-based bispecific agents have been associated with systemic cytokine release syndrome (CRS) including fever, constitutional symptoms, and in severe instances, hemodynamic compromise $[24,100,101]$. Substantive improvement in the management of CRS has been afforded by meticulous supportive care, with early and aggressive immunosuppression as indicated, including the use of neutralizing anti-TNF and/ or anti-IL-6 anti-cytokine antibodies. CAR T cell administration has also been associated with distinct, focal neurologic toxicity of uncertain etiology [102]. The experience derived from the management of AEs in patients treated with checkpoint inhibitors, cytokines, and CAR T cells has provided considerable insight that will enable future development of immunotherapy combinations. Common themes that have emerged from this experience highlight the importance of meticulous monitoring, early recognition and intervention with appropriate immune suppression, close collaboration between pharmaceutical sponsors and investigators in optimizing approaches for supportive care, and where appropriate, the implementation of algorithm-based supportive care regimens.

\section{Clinical trial design considerations}

Historically, clinical development of many oncology combinations has proceeded using traditional development paradigms, where individual molecules undergo rigorous clinical testing as monotherapy, and often, combination trials have been deferred until clear 
monotherapy proof-of-concept has been established. As such, single agent phase I and phase II trials with each agent were typically executed, and only then, would phase I/II trials be triggered to investigate specific combinations. In many instances, failure to demonstrate substantive monotherapy activity led to cessation of further clinical development. This approach has been well-established using small molecules, but may be less well-suited for some immunotherapy agents, where clinical development efforts can be terminated prematurely based on unrealistic expectations for monotherapy activity using conventional criteria. More recently, driven by increasing recognition of the potential of immunotherapeutic combinations, as well as the reality that some agents may yield only modest clinical activity as monotherapy yet be highly active in the context of a therapeutic combination, innovative trial designs have been deployed increasingly to test these agents $[103,104]$. These include run-in trial designs, zig-zag designs with or without de-escalation, and bifurcated designs among others. Run-in trial designs offer the prospect, where appropriate, for staged, sequential combination of an investigational agent with another standard-of-care drug, within the same patient after an initial monotherapy runin window. At the study level, run-in trial designs may offer the prospect for getting an initial characterization of monotherapy safety before each patient is exposed to the combination, and conceptually, may enable more rapid identification of the MTD for a regimen depending on the extent of dose escalation. This approach may be most appropriate when there is particularly well-substantiated data suggesting that the safety profile of a given combination is anticipated to be highly favorable, and the respective agents clearly have non-overlapping safety profiles. Such studies can be executed with or without the option for de-escalation, but are likely used most appropriately when deployed with the flexibility for dose de-escalation of either agent. So-called "zig-zag" escalation trials afford the flexibility to explore various dose combinations of the respective agents by alternating the increases in dosing of each agent during dose escalation. This design may be particularly useful when the key driver of the clinical activity and/or safety of a given combination is less clear or when there is an anticipation that a given combination may have a narrower therapeutic window. Bifurcated designs also have been used recently for the investigation of some immunotherapeutic combinations. These are particularly well-suited for the testing of combinations where it is anticipated that an investigational agent will have a modest safety profile and limited potential for monotherapy clinical activity, yet there is clear rationale that this agent may synergize when administered in combination with another drug. In this approach, monotherapy dose escalation is executed through several dose levels with the novel agent. Presuming acceptable safety, the trial may then "bifurcate" down two distinct paths for subsequent escalation. On one arm, continued monotherapy escalation of the novel agent is pursued as appropriate until the MTD, maximum biologically-effective dose (MBED), or maximum administered dose (MAD) is defined. In parallel, escalation of the combination is pursued on a second arm, typically by combining a dose of the novel agent that is 1-2 dose levels below the highest monotherapy dose that already has been shown to be safe, in combination with another agent. Escalation can then proceed using either a fixed dose of the second agent or can proceed using a "zig-zag" approach guided by features of the specific combination. This approach allows for more rapid triggering of combination testing in clinical development, but may not be appropriate for some combinations. Further, a bifurcated-design trial should typically be structured so that the dose of the novel agent being tested in the combination arm does not exceed the dose that has been deemed safe in the monotherapy arm of the study.

We are entering an exciting era for combination immunotherapy that offers the prospect to build upon the powerful proof-of-principle established by the clinical experience with combination checkpoint blockade. Several key considerations may play an important role in enabling future progress with this approach. These include: a) rigorous assessment of the optimal dose, sequence, and schedule of agents in both preclinical models and the clinical setting; b) flexible approaches to decision-making in the selection of dose and schedule, and application of this decision-making across multiple indications; c) recognition that some agents may have limited monotherapy clinical activity, yet have high potential for clinical activity in the setting of an immunotherapy combination; d) careful attention to supportive care, including education of both patients and all members of the health-care team regarding the importance of early recognition and intervention for the management of irAEs; and e) the use of properly designed trials that enable efficient testing of the safety and clinical activity of combination immunotherapy regimens.

\section{Endpoints \\ Safety}

Novel combinations present the possibility of enhanced efficacy compared with monotherapies, yet also the real risk of additional or even novel toxicities. The above sections addressed the issues to consider in terms of trial design to incorporate appropriate observation periods and dosing levels needed to accommodate these issues. When considering combination therapies, management algorithms for each agent to be combined should be readily available. The lessons learned from the clinical 
development of ipilimumab + nivolumab have included a demonstration of no new toxicities with the combination compared with monotherapies, while more patients experienced multiple irAEs. The prior development of mechanistic management algorithms for both combinatorial partners allowed for the investigation of this combination in a global phase III trial with no treatment-related deaths in the combination group [27]. The investigations of ipilimumab with vemurafenib and ipilimumab with dacarbazine were also important sources of lessons regarding safety profile expectations. In both instances, hepatic enzyme elevation was more common than expected. Both of the non-immunologic partners were previously known to have low hepatic AE rates. Yet, when combined with the CTLA-4 blocking antibody, this toxicity was considerably more common $[3,95]$. This should be kept in mind when considering cross-modality combinations.

\section{Efficacy}

Early in the development of ipilimumab, it became apparent that conventional radiographic response criteria were not capturing the full spectrum of biologic activity of the agent. Some patients were demonstrating atypical response with clear disease progression before significant response occurred and mixed responses with regression of index lesions despite the appearance of new areas of disease. Using modified World Health Organization (mWHO) or Response Evaluation Criteria in Solid Tumors (RECIST) assessment, either pattern is considered progressive disease. The underlying mechanism could be either transient enlargement due to lymphocytic infiltration or truly a delay in response due to the need for multiple epitopes to be recognized and responded to. With careful analysis, it was estimated that $15-25 \%$ of melanoma patients treated with ipilimumab who initially were classified as having disease progression, eventually had response or long-term disease stabilization and demonstrated long-term survival. This pattern has also been reported with the oncolytic virus, T-VEC, in patients with melanoma [20]. These observations led to the development of a proposed set of new response criteria, the immune-related response criteria (irRC) $[105,106]$. While the irRC are still considered non-validated and exploratory, it is also clear that a subset of patients treated with other immunotherapies (PD-1 pathway blocking agents) manifest similarly atypical response kinetics, albeit less frequently [107]. Given the clinical imperative for rapid drug development, the use of OS is becoming less practical as a sole primary endpoint. Therefore, combination studies have employed PFS and OS as co-primary endpoints as a means to capture early signals of high activity while also maintaining the importance of OS as the true measure of durability that is expected from immunotherapy. In the phase III study of T-VEC a primary clinical endpoint of durable response rate (DRR) was used, which incorporated both response rate (based on $\mathrm{mWHO}$ criteria) and time (duration $\geq 6$ months).

\section{Registration pathway}

The registration pathway for combination therapies can be considered in a variety of ways. The ipilimumab registration study (MDX-010-20) followed a 'contribution of components' model for testing ipilimumab, gp100 peptides or the combination. The study hypothesized that the combination would be superior to either monotherapy. In the end, the two ipilimumab-containing groups had similar OS. The presence of all three groups allowed for the ipilimumab monotherapy group to be evaluated for OS vs gp100 alone, therefore allowing for the possibility of demonstrating activity for multiple groups. This type of trial design is a clean route to prospectively assess combinations in the context of monotherapies but does lead to large studies. Other considerations in registration pathway designs include weighing the value of concurrent versus

Table 2 Critical issues in combination immunotherapy drug development

- Combination regimens should be based on scientific evidence of underlying tumor cell and immune system biology whenever possible. There is evidence that combinations within drug classes (e.g., T cell checkpoint inhibitors) and across classes may be clinically beneficial.

- Murine models have limitations but may be useful for early proof-of-principle for specific combination strategies and can be useful for understanding the biology and mechanisms of action for certain combinations. These models have generally not been useful for toxicity assessment.

- While combination therapy may be anticipated to improved therapeutic effectiveness, the approach may also increase the potential for adverse events. This possibility should be carefully considered in developing clinical study designs for combination immunotherapy.

- Innovative clinical study designs may be useful for early phase combination immunotherapy development. These may include dose escalation, dose de-escalation, zig-zag, run-in and sequential administration designs. A better understanding of the adverse event profile, as may be obtained from small monotherapy phase I studies, is helpful in optimizing the design of combination trials.

- The unique mechanism of action for immunotherapy agents suggests that new clinical endpoints may be needed for early phase drug development. The use of progressionfree survival may be misleading given the delayed kinetics of response that can occur with some agents and regimens. New endpoints, such as immune-related response criteria or durable response rate, may be better for predicting clinical benefit in late stage studies.

- Early and frequent discussion with regulatory agencies should be considered for combination immunotherapy regimens.

- Other issues, such as intellectual property, conflict of interest, quality of life, patientreported outcomes, and the financial costs vs. overall health benefits as defined in the value proposition of combination immunotherapy, will be important issues for further discussion. 
sequential schedules. Another niche for combination drug development is the 'add-in' design where a new agent is added at the time of progression on the 'foundational' agent. Given that all patients treated with the combination will have progressive disease when beginning combination therapy, a modest degree of clinical activity with the additional agent could represent a rapid route to registration. One other consideration in designing combination registration pathways is that combination immunotherapy may have a different degree of tolerability in patients with different malignancies. Therefore, flexibility in dose levels and frequency needs to be considered when evaluating combinations across different disease types. Early and more frequent dialogue with regulatory agencies may also be helpful in designing and conducting combination immunotherapy clinical trials.

\section{Conclusions}

The number of cancer patients who benefit from immunotherapy has increased due to a better understanding of the immune response to cancer along with recent advances in biomarker development. The goal of combination approaches is to expand the spectrum of patients who respond to cancer immunotherapy (more responding patients in tumors that are sensitive to monotherapy and the identification of new sensitive tumor types that do not respond to monotherapy alone) and to improve the quality of clinical responses (i.e., extension of response duration, PFS, and OS) beyond what can be achieved with monotherapy alone. With research to further elucidate the mechanisms of action behind these agents as well as increased understanding of the resistant counter defense employed by tumors, the development of rational combination approaches is now extending even beyond doublets. Novel triplet regimens of synergistic combinations of immunotherapy agents as well as immunotherapy with conventional or targeted therapies are being investigated in a variety of disease settings. There is tremendous potential for these approaches to extend the clinical success of immunotherapies. However, the added benefit of each additional drug must be properly evaluated against the added toxicities as well as economic impact of the cost of these strategies (the "value proposition"). Previous experience also demonstrates that combination approaches should not be developed solely on the standard dosing and regimens of single agents. Instead, there is a need to investigate the dose and schedule of combination immunotherapies thoroughly and with added flexibility to optimize the dose, schedule, and configuration of each agent. Moreover, the optimal dose and schedule for a given combination may differ across disease indications. Although pre-clinical animal models have limitations, they can be useful for assessing the therapeutic potential of specific combination regimens, interrogating the mechanism of action, and providing insight into the underlying biology of various therapeutic strategies. Progress in combination immunotherapy will also depend on thorough clinical testing, with proper clinical trial design and endpoints. The SITC Combination Therapies Taskforce has summarized the critical issues currently facing the clinical development of combination immunotherapy (Table 2). These issues should help focus further development and promote discussion among academic, industry, and regulatory partners to more fully realize the potential of combination immunotherapy for the treatment of cancer.

\section{Abbreviations \\ 4-HT: 4-hydroxytamoxifen; AE: Adverse events; CAR: Chimeric-antigen receptor; CRS: Cytokine release syndrome; CTLA-4: Cytotoxic T lymphocyte associated protein 4; DC: Dendritic cell; DLT: Dose-limiting toxicity; DMBA: 7,12-dimethylbenz[a]anthracene; DRR: Durable response rate; DT: Diphtheria toxin; FOXN1: Forkhead box protein N1; GEMM: Genetically engineered mouse model; GITR: Glucocorticoid-induced tumor necrosis factor receptor-related protein; GVHD: Graft-versus-host disease; \\ IDO: Indoleamine 2,3-dioxgenase; IL: Interleukin; irAE: Immune-related adverse event; IRB: Institutional review board; irRC: Immune-related response criteria; MAD: Maximum administered dose; MBED: Maximum biologically- effective dose; MCA: Methylcholanthrene; MDSC: Myeloid derived suppressor cells; MSI: Microsatellite instability; MT: Metallothionein-l; MTD: Maximum tolerated dose; mWHO: Modified World Health Organization; NK: Natural killer cell; NKT: Natural killer T cell; NSCLC: Non-small cell lung cancer; ORR: Objective response rate; OS: Overall survival; PD-1: Programed cell death 1; PD-L1: Programed cell death ligand 1; PFS: Progression-free survival; PyMT: Polyoma middle T antigen; RAG-1: Recombination activation gene; RECIST: Response evaluation criteria in solid tumors; SCID: Severe combined immunodeficiencies; SITC: Society for Immunotherapy of Cancer; SV40: Simian virus 40; TPA: 12-O-tetradecanoylphorbol-13-acetate; Treg: Regulatory T cell; T- VEC: Talimogene laherparepvec}

\section{Acknowledgements}

The authors would like to express their gratitude to Holbrook Edwin Kidd Kohrt, MD, PhD (1977-2016), who originally lead this initiative by serving as the chair of SITC's Combination Immunotherapy Task Force.

\section{Funding}

Not applicable.

\section{Availability of data and materials}

Not applicable.

\section{Authors' contributions}

This manuscript is the result of the combined effort of the SITC Combination Immunotherapy Task Force. PAO, SH, HLK, and JMW drafted portions of the manuscript. All authors participated in the conceptualization, critical review, and editing of this paper. In addition, all authors read and approved the final version of this manuscript.

\section{Competing interests}

PAO has received institutional research funding from Merck, Bristol-Myers Squibb, Celldex, ArmoBiosciences, and AstraZeneca/Medlmmune. He has also acted as a consultant to Neon Therapeutics, Bristol-Myers Squibb, Celldex, CytomX, Amgen, Alexion, and Genentech. FSH has received institutional research funding from Bristol-Myers Squibb and has acted as a consultant to Genentech-Roche, Merck, Novartis, and EMD Serono. HLK has acted as a consultant to Amgen, EMD Serono, Merck, Prometheus Laboratories, Sanofi Aventis, and Celldex. He is also currently employed and receives salary from Compass Therapeutics. JMW receives salary and holds stock options at Macrogenics, Inc. JDW has acted as a consultant and has received research funding from Bristol-Myers Squibb, Medlmmune, Merck, and Genentech. 


\section{Consent for publication}

Not applicable.

\section{Ethics approval and consent to participate}

Not applicable.

\section{Author details}

'Dana-Farber Cancer Institute, Harvard Medical School, 450 Brookline Avenue, Dana540C, Boston, MA 02215, USA. ${ }^{2}$ Rutgers Cancer Institute of New Jersey, 195 Little Albany Street, New Brunswick, NJ 08901, USA.

${ }^{3}$ MacroGenics, Inc., 9640 Medical Center Drive, Rockville, MD 20850, USA. ${ }^{4}$ Memorial Sloan Kettering Cancer Center, 1275 York Avenue, Z-1503, New York, NY 10065, USA.

\section{Received: 28 October 2016 Accepted: 1 February 2017} Published online: 21 February 2017

\section{References}

1. Sharma P, Allison JP. The future of immune checkpoint therapy. Science. 2015;348(6230):56-61. doi:10.1126/science.aaa8172.

2. Hodi FS, O'Day SJ, McDermott DF, Weber RW, Sosman JA, Haanen JB, et al. Improved survival with ipilimumab in patients with metastatic melanoma. N Engl J Med. 2010;363(8):711-23. doi:10.1056/NEJMoa1003466.

3. Robert C, Thomas L, Bondarenko I, O'Day S, Weber J, Garbe C, et al. Ipilimumab plus dacarbazine for previously untreated metastatic melanoma. N Engl J Med. 2011;364(26):2517-26. doi:10.1056/NEJMoa1104621.

4. Topalian SL, Hodi FS, Brahmer JR, Gettinger SN, Smith DC, McDermott DF, et al. Safety, activity, and immune correlates of anti-PD-1 antibody in cancer. N Engl J Med. 2012;366(26):2443-54. doi:10.1056/NEJMoa1200690.

5. Brahmer JR, Tykodi SS, Chow LQ, Hwu WJ, Topalian SL, Hwu P, et al. Safety and activity of anti-PD-L1 antibody in patients with advanced cancer. N Engl J Med. 2012;366(26):2455-65. doi:10.1056/NEJMoa1200694.

6. Garon EB, Rizvi NA, Hui R, Leighl N, Balmanoukian AS, Eder JP, et al. Pembrolizumab for the treatment of non-small-cell lung cancer. N Engl J Med. 2015;372(21):2018-28. doi:10.1056/NEJMoa1501824.

7. Rizvi NA, Hellmann MD, Snyder A, Kvistborg P, Makarov V, Havel J, et al. Cancer immunology. Mutational landscape determines sensitivity to PD-1 blockade in non-small cell lung cancer. Science. 2015;348(6230):124-8. doi:10.1126/science.aaa1348.

8. Le DT, Uram JN, Wang H, Bartlett BR, Kemberling H, Eyring AD, et al. PD-1 blockade in tumors with mismatch-repair deficiency. N Engl J Med. 2015; 372(26):2509-20. doi:10.1056/NEJMoa1500596.

9. Van Allen EM, Miao D, Schilling B, Shukla SA, Blank C, Zimmer L, et al. Genomic correlates of response to CTLA-4 blockade in metastatic melanoma. Science. 2015;350(6257):207-11. doi:10.1126/science.aad0095.

10. Chen J, Creasy C, Torres-Cabala CA, Ekmekcioglu S, Maiti SN, Kale C, et al. Predictive immune biomarker signatures in the tumor microenvironment of melanoma metastases associated with tumor-infiltrating lymphocyte (TIL) therapy. J Immunother Cancer. 2014;2 Suppl 3:P243-P. doi:10.1186/2051-1426-2-S3-P243.

11. Chen PL, Roh W, Reuben A, Cooper ZA, Spencer CN, Prieto PA, et al. Analysis of immune signatures in longitudinal tumor samples yields insight into biomarkers of response and mechanisms of resistance to immune checkpoint blockade. Cancer Discov. 2016;6(8):827-37. doi:10.1158/2159-8290.cd-15-1545.

12. Spranger $S$, Bao R, Gajewski TF. Melanoma-intrinsic beta-catenin signalling prevents anti-tumour immunity. Nature. 2015;523:231-5. doi:10.1038/nature14404.

13. Snyder A, Wolchok JD, Chan TA. Genetic basis for clinical response to CTLA4 blockade. N Engl J Med. 2015;372(8):783. doi:10.1056/NEJMc1415938.

14. Schumacher TN, Schreiber RD. Neoantigens in cancer immunotherapy. Science. 2015;348(6230):69-74. doi:10.1126/science.aaa4971.

15. Andtbacka RH, Kaufman HL, Collichio F, Amatruda T, Senzer N, Chesney J, et al. Talimogene laherparepvec improves durable response rate in patients with advanced melanoma. J Clin Oncol. 2015;33:2780-8. doi:10.1200/JCO.2014.58.3377.

16. Puzanov I, Milhem MM, Minor D, Hamid O, Li A, Chen L, et al. Talimogene laherparepvec in combination with ipilimumab in previously untreated, unresectable stage IIIB-IV melanoma. J Clin Oncol. 2016;34(22):2619-26. doi:10.1200/jco.2016.67.1529.

17. Long GV. Primary analysis of MASTERKEY-265 phase 1b study of talimogene laherparepvec (T-VEC) and pembrolizumab (pembro) for unresectable stage
IIIB-IV melanoma. Society for Melanoma Research 2015 Congress. 2015; November 18-21(San Fransciso, California).

18. Goodwin RG, Din WS, Davis-Smith T, Anderson DM, Gimpel SD, Sato TA, et al. Molecular cloning of a ligand for the inducible $T$ cell gene 4-1BB: a member of an emerging family of cytokines with homology to tumor necrosis factor. Eur J Immunol. 1993;23(10):2631-41. doi:10.1002/eji.1830231037.

19. Curti BD, Kovacsovics-Bankowski M, Morris N, Walker E, Chisholm L, Floyd $\mathrm{K}$, et al. OX40 is a potent immune-stimulating target in latestage cancer patients. Cancer Res. 2013;73(24):7189-98. doi:10.1158/ 0008-5472.CAN-12-4174.

20. Melero I, Hirschhorn-Cymerman D, Morales-Kastresana A, Sanmamed MF, Wolchok JD. Agonist antibodies to TNFR molecules that costimulate T and NK cells. Clin Cancer Res. 2013;19(5):1044-53. doi:10.1158/1078-0432.CCR-12-2065.

21. Wei H, Zhao L, Li W, Fan K, Qian W, Hou S, et al. Combinatorial PD-1 blockade and CD137 activation has therapeutic efficacy in murine cancer models and synergizes with cisplatin. PLoS One. 2013;8(12):e84927. doi:10.1371/journal.pone.0084927.

22. Ascierto PA, Simeone E, Sznol M, Fu YX, Melero I. Clinical experiences with anti-CD137 and anti-PD1 therapeutic antibodies. Semin Oncol. 2010;37(5): 508-16. doi:10.1053/.j.seminoncol.2010.09.008.

23. Maude SL, Frey N, Shaw PA, Aplenc R, Barrett DM, Bunin NJ, et al. Chimeric antigen receptor T cells for sustained remissions in leukemia. N Engl J Med. 2014;371(16):1507-17. doi:10.1056/NEJMoa1407222.

24. Porter $\mathrm{DL}$, Levine $\mathrm{BL}$, Kalos $\mathrm{M}$, Bagg $\mathrm{A}$, June $\mathrm{CH}$. Chimeric antigen receptormodified T cells in chronic lymphoid leukemia. N Engl J Med. 2011;365(8): 725-33. doi:10.1056/NEJMoa1103849.

25. Rosenberg SA, Restifo NP. Adoptive cell transfer as personalized immunotherapy for human cancer. Science. 2015;348(6230):62-8. doi:10.1126/science.aaa4967.

26. Curran MA, Montalvo W, Yagita H, Allison JP. PD-1 and CTLA-4 combination blockade expands infiltrating $T$ cells and reduces regulatory $T$ and myeloid cells within B16 melanoma tumors. Proc Natl Acad Sci U S A. 2010;107(9): 4275-80. doi:10.1073/pnas.0915174107.

27. Larkin J, Chiarion-Sileni V, Gonzalez R, Grob JJ, Cowey CL, Lao CD, et al. Combined nivolumab and ipilimumab or monotherapy in untreated melanoma. N Engl J Med. 2015;373(1):23-34. doi:10.1056/NEJMoa1504030.

28. Postow MA, Chesney J, Pavlick AC, Robert C, Grossmann K, McDermott D, et al. Nivolumab and ipilimumab versus ipilimumab in untreated melanoma. N Engl J Med. 2015;372(21):2006-17. doi:10.1056/NEJMoa1414428.

29. Hu-Lieskovan S, Robert L, Homet Moreno B, Ribas A. Combining targeted therapy with immunotherapy in BRAF-mutant melanoma: promise and challenges. J Clin Oncol. 2014;32(21):2248-54. doi:10.1200/JCO.2013.52.1377.

30. Frederick DT, Piris A, Cogdill AP, Cooper ZA, Lezcano C, Ferrone CR, et al. BRAF inhibition is associated with enhanced melanoma antigen expression and a more favorable tumor microenvironment in patients with metastatic melanoma. Clin Cancer Res. 2013;19(5):1225-31. doi:10.1158/1078-0432.CCR-12-1630.

31. Kandalaft LE, Motz GT, Busch J, Coukos G. Angiogenesis and the tumor vasculature as antitumor immune modulators: the role of vascular endothelial growth factor and endothelin. Curr Top Microbiol Immunol. 2011;344:129-48. doi:10.1007/82_2010_95.

32. Ohm JE, Carbone DP. VEGF as a mediator of tumor-associated immunodeficiency. Immunol Res. 2001;23(2-3):263-72. doi:10.1385/IR:23:2-3:263

33. Ott PA, Hodi FS, Buchbinder El. Inhibition of immune checkpoints and vascular endothelial growth factor as combination therapy for metastatic melanoma: an overview of rationale, preclinical evidence, and initial clinical data. Front Oncol. 2015;5:202. doi:10.3389/fonc.2015.00202.

34. Hodi FS, Lawrence D, Lezcano C, Wu X, Zhou J, Sasada T, et al. Bevacizumab plus ipilimumab in patients with metastatic melanoma. Cancer Immunol Res. 2014;2(7):632-42. doi:10.1158/2326-6066.CIR-14-0053.

35. Formenti SC, Demaria S. Combining radiotherapy and cancer immunotherapy: a paradigm shift. J Natl Cancer Inst. 2013;105(4):256-65. doi:10.1093/jnci/djs629.

36. Demaria S, Kawashima N, Yang AM, Devitt ML, Babb JS, Allison JP, et al. Immune-mediated inhibition of metastases after treatment with local radiation and CTLA-4 blockade in a mouse model of breast cancer. Clin Cancer Res. 2005;11(2 Pt 1):728-34.

37. Dewan MZ, Galloway AE, Kawashima N, Dewyngaert JK, Babb JS, Formenti SC, et al. Fractionated but not single-dose radiotherapy induces an immune- 
mediated abscopal effect when combined with anti-CTLA-4 antibody. Clin Cancer Res. 2009;15(17):5379-88. doi:10.1158/1078-0432.CCR-09-0265.

38. Postow MA, Callahan MK, Barker CA, Yamada Y, Yuan J, Kitano S, et al. Immunologic correlates of the abscopal effect in a patient with melanoma. N Engl J Med. 2012;366(10):925-31. doi:10.1056/NEJMoa1112824.

39. Twyman-Saint Victor C, Rech AJ, Maity A, Rengan R, Pauken KE, Stelekati E, et al. Radiation and dual checkpoint blockade activate non-redundant immune mechanisms in cancer. Nature. 2015;520(7547):373-7. doi:10.1038/nature14292.

40. Munn DH, Shafizadeh E, Attwood JT, Bondarev I, Pashine A, Mellor AL. Inhibition of T cell proliferation by macrophage tryptophan catabolism. Exp Med. 1999;189(9):1363-72.

41. Sharma MD, Baban B, Chandler P, Hou DY, Singh N, Yagita H, et al. Plasmacytoid dendritic cells from mouse tumor-draining lymph nodes directly activate mature Tregs via indoleamine 2,3-dioxygenase. J Clin Invest. 2007;117(9):2570-82. doi:10.1172/JC|31911.

42. Munn DH, Sharma MD, Hou D, Baban B, Lee JR, Antonia SJ, et al. Expression of indoleamine 2,3-dioxygenase by plasmacytoid dendritic cells in tumordraining lymph nodes. J Clin Invest. 2004;114(2):280-90. doi:10.1172/ JCl21583.

43. Uyttenhove C, Pilotte L, Theate I, Stroobant V, Colau D, Parmentier N, et al. Evidence for a tumoral immune resistance mechanism based on tryptophan degradation by indoleamine 2,3-dioxygenase. Nat Med. 2003;9(10):1269-74. doi:10.1038/nm934.

44. Taylor MW, Feng GS. Relationship between interferon-gamma, indoleamine 2,3-dioxygenase, and tryptophan catabolism. FASEB J. 1991;5(11):2516-22.

45. Incyte. Incyte and Merck to Advance Clinical Development Program Investigating the Combination of Epacadostat with KEYTRUDA (pembrolizumab). January 9, 2017. http:/www.incyte.com/media/recent-news.aspx. Accessed 23 Jan 2017.

46. Zitvogel L, Kepp O, Kroemer G. Immune parameters affecting the efficacy of chemotherapeutic regimens. Nat Rev Clin Oncol. 2011;8(3):151-60. doi:10. 1038/nrclinonc.2010.223

47. Inaba K, Inaba M, Romani N, Aya H, Deguchi M, Ikehara S, et al. Generation of large numbers of dendritic cells from mouse bone marrow cultures supplemented with granulocyte/macrophage colony-stimulating factor. J Exp Med. 1992;176(6):1693-702.

48. Paquette RL, Hsu NC, Kiertscher SM, Park AN, Tran L, Roth MD, et al. Interferon-alpha and granulocyte-macrophage colony-stimulating factor differentiate peripheral blood monocytes into potent antigen-presenting cells. J Leukoc Biol. 1998;64(3):358-67.

49. Hodi FS, Lee S, McDermott DF, Rao UN, Butterfield LH, Tarhini AA, et al. Ipilimumab plus sargramostim vs ipilimumab alone for treatment of metastatic melanoma: a randomized clinical trial. JAMA. 2014;312(17):1744-53. doi:10.1001/jama.2014.13943.

50. Tarhini AA, Cherian J, Moschos SJ, Tawbi HA, Shuai Y, Gooding WE, et al. Safety and efficacy of combination immunotherapy with interferon alfa-2b and tremelimumab in patients with stage IV melanoma. J Clin Oncol. 2012; 30(3):322-8. doi:10.1200/JCO.2011.37.5394.

51. Maker AV, Phan GQ, Attia P, Yang JC, Sherry RM, Topalian SL, et al. Tumor regression and autoimmunity in patients treated with cytotoxic $T$ lymphocyte-associated antigen 4 blockade and interleukin 2: a phase 1/ll study. Ann Surg Oncol. 2005;12(12):1005-16. doi:10.1245/aso.2005.03.536.

52. Devaud C, Westwood JA, John LB, Flynn JK, Paquet-Fifield S, Duong CP, et al. Tissues in different anatomical sites can sculpt and vary the tumor microenvironment to affect responses to therapy. Mol Ther. 2014;22(1):18-27. doi:10.1038/mt.2013.219.

53. Dranoff G. Experimental mouse tumour models: what can be learnt about human cancer immunology? Nat Rev Immunol. 2012;12(1):61-6. doi:10. 1038/nri3129.

54. DuPage M, Jacks T. Genetically engineered mouse models of cancer reveal new insights about the antitumor immune response. Curr Opin Immunol. 2013;25(2):192-9. doi:10.1016/j.coi.2013.02.005.

55. Fantozzi A, Christofori G. Mouse models of breast cancer metastasis. Breast Cancer Res. 2006;8(4):212. doi:10.1186/bcr1530

56. Eyles J, Puaux AL, Wang X, Toh B, Prakash C, Hong M, et al. Tumor cells disseminate early, but immunosurveillance limits metastatic outgrowth, in a mouse model of melanoma. J Clin Invest. 2010;120(6):2030-9. doi:10.1172/ jci42002.

57. Knight DA, Ngiow SF, Li M, Parmenter T, Mok S, Cass A, et al. Host immunity contributes to the anti-melanoma activity of BRAF inhibitors. J Clin Invest. 2016;126(1):402-3. doi:10.1172/jci84828.
58. Kato M, Takahashi M, Akhand AA, Liu W, Dai Y, Shimizu S, et al. Transgenic mouse model for skin malignant melanoma. Oncogene. 1998;17(14):1885-8. doi:10.1038/sj.onc.1202077.

59. DuPage M, Cheung AF, Mazumdar C, Winslow MM, Bronson R, Schmidt LM, et al. Endogenous $\mathrm{T}$ cell responses to antigens expressed in lung adenocarcinomas delay malignant tumor progression. Cancer Cell. 2011; 19(1):72-85. doi:10.1016/j.ccr.2010.11.011.

60. DuPage M, Mazumdar C, Schmidt LM, Cheung AF, Jacks T. Expression of tumour-specific antigens underlies cancer immunoediting. Nature. 2012; 482(7385):405-9. doi:10.1038/nature10803.

61. Matsushita H, Vesely MD, Koboldt DC, Rickert CG, Uppaluri R, Magrini VJ, et al. Cancer exome analysis reveals a T-cell-dependent mechanism of cancer immunoediting. Nature. 2012;482(7385):400-4. doi:10.1038/nature10755.

62. Flanagan SP. 'Nude', a new hairless gene with pleiotropic effects in the mouse. Genet Res. 1966;8(3):295-309.

63. Balciunaite G, Keller MP, Balciunaite E, Piali L, Zuklys S, Mathieu YD, et al. Wnt glycoproteins regulate the expression of FoxN1, the gene defective in nude mice. Nat Immunol. 2002;3(11):1102-8. doi:10.1038/ni850.

64. Mombaerts P, lacomini J, Johnson RS, Herrup K, Tonegawa S, Papaioannou VE. RAG-1-deficient mice have no mature B and T lymphocytes. Cell. 1992; 68(5):869-77.

65. Xie Y, Akpinarli A, Maris C, Hipkiss EL, Lane M, Kwon EK, et al. Naive tumorspecific CD4(+) T cells differentiated in vivo eradicate established melanoma. J Exp Med. 2010;207(3):651-67. doi:10.1084/jem.20091921.

66. Goding SR, Wilson KA, Xie Y, Harris KM, Baxi A, Akpinarli A, et al. Restoring immune function of tumor-specific CD4+ T cells during recurrence of melanoma. J Immunol. 2013;190(9):4899-909. doi:10.4049/jimmunol. 1300271.

67. Antony PA, Piccirillo CA, Akpinarli A, Finkelstein SE, Speiss PJ, Surman DR, et al. CD8+ T cell immunity against a tumor/self-antigen is augmented by CD4 $+T$ helper cells and hindered by naturally occurring $T$ regulatory cells. J Immunol. 2005;174(5):2591-601.

68. Finnie NJ, Gottlieb TM, Blunt T, Jeggo PA, Jackson SP. DNA-dependent protein kinase activity is absent in xrs-6 cells: implications for site-specific recombination and DNA double-strand break repair. Proc Natl Acad Sci U S A. 1995:92(1):320-4.

69. Kirchgessner CU, Patil CK, Evans JW, Cuomo CA, Fried LM, Carter T, et al. DNA-dependent kinase (p350) as a candidate gene for the murine SCID defect. Science. 1995;267(5201):1178-83.

70. Shultz LD, Lyons BL, Burzenski LM, Gott B, Chen X, Chaleff S, et al. Human lymphoid and myeloid cell development in NOD/LtSz-scid IL2R gamma null mice engrafted with mobilized human hemopoietic stem cells. J Immunol. 2005;174(10):6477-89.

71. Ishikawa F, Yasukawa M, Lyons B, Yoshida S, Miyamoto T, Yoshimoto G, et al. Development of functional human blood and immune systems in NOD/ SCID/L2 receptor \{gamma\} chain(null) mice. Blood. 2005;106(5):1565-73. doi:10.1182/blood-2005-02-0516.

72. Ito R, Takahashi T, Katano I, Ito M. Current advances in humanized mouse models. Cell Mol Immunol. 2012;9(3):208-14. doi:10.1038/cmi.2012.2.

73. Overwijk WW, Lee DS, Surman DR, Irvine KR, Touloukian CE, Chan CC, et al. Vaccination with a recombinant vaccinia virus encoding a "self" antigen induces autoimmune vitiligo and tumor cell destruction in mice: requirement for CD4(+) T lymphocytes. Proc Natl Acad Sci U S A. 1999;96(6): $2982-7$.

74. Iwama S, De Remigis A, Callahan MK, Slovin SF, Wolchok JD, Caturegli P. Pituitary expression of CTLA-4 mediates hypophysitis secondary to administration of CTLA-4 blocking antibody. Sci Transl Med. 2014;6(230): 230ra45. doi:10.1126/scitranslmed.3008002.

75. Teng MW, Ngiow SF, von Scheidt B, McLaughlin N, Sparwasser T, Smyth MJ. Conditional regulatory $\mathrm{T}$-cell depletion releases adaptive immunity preventing carcinogenesis and suppressing established tumor growth. Cancer Res. 2010;70(20):7800-9. doi:10.1158/0008-5472.can-10-1681.

76. Lahl K, Sparwasser T. In vivo depletion of FoxP3+ Tregs using the DEREG mouse model. Methods Mol Biol. 2011;707:157-72. doi:10.1007/978-1-61737-979-6_10.

77. Budhu S, Wolchok J, Merghoub T. The importance of animal models in tumor immunity and immunotherapy. Curr Opin Genet Dev. 2014;24:46-51. doi:10.1016/j.gde.2013.11.008.

78. Hamid O, Robert C, Daud A, Hodi FS, Hwu WJ, Kefford R, et al. Safety and tumor responses with lambrolizumab (anti-PD-1) in melanoma. N Engl J Med. 2013;369(2):134-44. doi:10.1056/NEJMoa1305133. 
79. McDermott DF, Sosman JA, Sznol M, Massard C, Gordon MS, Hamid O, et al. Atezolizumab, an anti-programmed death-ligand 1 antibody, in metastatic renal cell carcinoma: long-term safety, clinical activity, and immune correlates from a phase la study. J Clin Oncol. 2016;34(8):833-42. doi:10.1200/jco.2015.63.7421.

80. Kohrt HE, Houot R, Goldstein MJ, Weiskopf K, Alizadeh AA, Brody J, et al. CD137 stimulation enhances the antilymphoma activity of anti-CD20 antibodies. Blood. 2011;117(8):2423-32. doi:10.1182/blood-2010-08-301945.

81. Kohrt HE, Houot R, Weiskopf K, Goldstein MJ, Scheeren F, Czerwinski D, et al. Stimulation of natural killer cells with a CD137-specific antibody enhances trastuzumab efficacy in xenotransplant models of breast cancer. J Clin Invest. 2012;122(3):1066-75. doi:10.1172/jci61226.

82. Curran MA, Kim M, Montalvo W, Al-Shamkhani A, Allison JP. Combination CTLA-4 blockade and 4-1BB activation enhances tumor rejection by increasing T-cell infiltration, proliferation, and cytokine production. PLoS One. 2011;6(4):e19499. doi:10.1371/journal.pone.0019499.

83. Hurwitz AA, Foster BA, Kwon ED, Truong T, Choi EM, Greenberg NM, et al. Combination immunotherapy of primary prostate cancer in a transgenic mouse model using CTLA-4 blockade. Cancer Res. 2000;60(9):2444-8.

84. Selby M, Engelhardt J, Lu L-S, Quigley M, Wang C, Chen B et al. Antitumor activity of concurrent blockade of immune checkpoint molecules CTLA-4 and PD-1 in preclinical models. J Clin Oncol. 2013;31 (2013 (suppl; abstr 3061)).

85. Woo SR, Turnis ME, Goldberg MV, Bankoti J, Selby M, Nirschl CJ, et al. Immune inhibitory molecules LAG-3 and PD-1 synergistically regulate T-cell function to promote tumoral immune escape. Cancer Res. 2012;72(4): 917-27. doi:10.1158/0008-5472.can-11-1620.

86. Salcedo R, Hixon JA, Stauffer JK, Jalah R, Brooks AD, Khan T, et al. Immunologic and therapeutic synergy of IL-27 and IL-2: enhancement of T cell sensitization, tumor-specific CTL reactivity and complete regression of disseminated neuroblastoma metastases in the liver and bone marrow. J Immunol. 2009;182(7):4328-38. doi:10.4049/jimmunol.0800471.

87. Murphy WJ, Welniak L, Back T, Hixon J, Subleski J, Seki N, et al. Synergistic anti-tumor responses after administration of agonistic antibodies to CD40 and IL-2: coordination of dendritic and CD8+ cell responses. J Immunol. 2003;170(5):2727-33.

88. Wigginton JM, Komschlies KL, Back TC, Franco JL, Brunda MJ, Wiltrout RH. Administration of interleukin 12 with pulse interleukin 2 and the rapid and complete eradication of murine renal carcinoma. J Natl Cancer Inst. 1996; 88(1):38-43

89. Guo Z, Wang X, Cheng D, Xia Z, Luan M, Zhang S. PD-1 blockade and OX40 triggering synergistically protects against tumor growth in a murine model of ovarian cancer. PLoS One. 2014;9(2):e89350. doi:10.1371/journal.pone.0089350.

90. Wolchok JD, Kluger H, Callahan MK, Postow MA, Rizvi NA, Lesokhin AM, et al. Nivolumab plus ipilimumab in advanced melanoma. N Engl J Med. 2013; 369(2):122-33. doi:10.1056/NEJMoa1302369.

91. Antonia SJ, Gettinger SN, Chow LQM, Juergens RA, Borghaei $H$, Shen $Y$ et al. Nivolumab (anti-PD-1; BMS-936558, ONO-4538) and ipilimumab in first-line NSCLC: Interim phase I results. J Clin Oncol. 2014;32(2014 (suppl; abstr 8023)).

92. Sampson JH, Vlahovic G, Sahebjam S, Omuro AMP, Baehring JM, Hafler DA et al. Preliminary safety and activity of nivolumab and its combination with ipilimumab in recurrent glioblastoma (GBM): CHECKMATE-143. J Clin Oncol. 2015;33(2015 (suppl; abstr 3010)).

93. Antonia S, Goldberg SB, Balmanoukian A, Chaft JE, Sanborn RE, Gupta A, et al. Safety and antitumour activity of durvalumab plus tremelimumab in non-small cell lung cancer: a multicentre, phase $1 \mathrm{~b}$ study. Lancet Oncol. 2016;17(3):299-308. doi:10.1016/s1470-2045(15)00544-6.

94. Sznol M, Kluger HM, Callahan MK, Postow MA, Gordon RA, Segal NH, et al. Survival, response duration, and activity by BRAF mutation (MT) status of nivolumab (NIVO, anti-PD-1, BMS-936558, ONO-4538) and ipilimumab (IPI) concurrent therapy in advanced melanoma (MEL). J Clin Oncol. 2014;32:5s (2014 (suppl; abstr LBA9003^)).

95. Ribas A, Hodi FS, Callahan M, Konto C, Wolchok J. Hepatotoxicity with combination of vemurafenib and ipilimumab. N Engl J Med. 2013;368(14): 1365-6. doi:10.1056/NEJMc1302338

96. Amin A, Lawson DH, Salama AK, Koon HB, Guthrie TH, Thomas SS et al. A single-arm, open-label, phase II study to evaluate the safety of vemurafenib (VEM) followed by ipilimumab (IPI) in BRAF V600mutated metastatic melanoma (MM). J Clin Oncol. 2015:33(2015 (suppl; abstr 9032)).
97. Rizvi N, Gettinger S, Goldman J, al.; e. Safety and efficacy of first-line nivolumab and ipilimumab in non-small cell lung cancer. 16th World Conference on Lung Cancer. Presented at: 16th World Conference on Lung Cancer. 2015;September 6-9(Denver, CO. Abstract 786.).

98. Bertrand A, Kostine M, Barnetche T, Truchetet ME, Schaeverbeke T. Immune related adverse events associated with anti-CTLA-4 antibodies: systematic review and meta-analysis. BMC Med. 2015;13:211. doi:10.1186/s12916-0150455-8.

99. Naidoo J, Page DB, Li BT, Connell LC, Schindler K, Lacouture ME, et al. Toxicities of the anti-PD-1 and anti-PD-L1 immune checkpoint antibodies. Ann Oncol. 2015;26(12):2375-91. doi:10.1093/annonc/mdv383.

100. Topp MS, Gokbuget N, Stein AS, Zugmaier G, O'Brien S, Bargou RC, et al. Safety and activity of blinatumomab for adult patients with relapsed or refractory B-precursor acute lymphoblastic leukaemia: a multicentre, singlearm, phase 2 study. Lancet Oncol. 2015;16(1):57-66. doi:10.1016/s14702045(14)71170-2.

101. Grupp SA, Kalos M, Barrett D, Aplenc R, Porter DL, Rheingold SR, et al. Chimeric antigen receptor-modified T cells for acute lymphoid leukemia. N Engl J Med. 2013;368(16):1509-18. doi:10.1056/NEJMoa1215134.

102. Bonifant $\mathrm{CL}$, Jackson HJ, Brentjens RJ, Curran KJ. Toxicity and management in CAR T-cell therapy. Mol Ther Oncolytics. 2016;3:16011. doi:10.1038/mto. 2016.11.

103. Bates SE, Berry DA, Balasubramaniam S, Bailey S, LoRusso PM, Rubin EH. Advancing clinical trials to streamline drug development. Clin Cancer Res. 2015;21(20):4527-35. doi:10.1158/1078-0432.ccr-15-0039.

104. Emens LA, Butterfield LH, Hodi Jr FS, Marincola FM, Kaufman HL. Cancer immunotherapy trials: leading a paradigm shift in drug development. J Immunother Cancer. 2016;4:42. doi:10.1186/s40425-016-0146-9.

105. Wolchok JD, Hoos A, O'Day S, Weber JS, Hamid O, Lebbe C, et al. Guidelines for the evaluation of immune therapy activity in solid tumors: immunerelated response criteria. Clin Cancer Res. 2009;15(23):7412-20. doi:10.1158/ 1078-0432.ccr-09-1624.

106. Hoos A, Eggermont AM, Janetzki S, Hodi FS, Ibrahim R, Anderson A, et al. Improved endpoints for cancer immunotherapy trials. J Natl Cancer Inst. 2010;102(18):1388-97. doi:10.1093/jnci/dja310.

107. Wolchok J, Chiarion-Sileni V, Gonzalez R, Rutkowski P, Grob J, Cowey C et al. Efficacy and safety results from a phase III trial of nivolumab (NIVO) alone or combined with ipilimumab (IPI) versus IPI alone in treatment-naive patients (pts) with advanced melanoma (MEL) (CheckMate 067). 2015;33((suppl; abstr LBA1)).

\section{Submit your next manuscript to BioMed Central and we will help you at every step:}

- We accept pre-submission inquiries

- Our selector tool helps you to find the most relevant journal

- We provide round the clock customer support

- Convenient online submission

- Thorough peer review

- Inclusion in PubMed and all major indexing services

- Maximum visibility for your research

Submit your manuscript at www.biomedcentral.com/submit
Biomed Central 